\title{
Numerical investigation of pressure drop and heat transfer in pin fin heat sink and micro channel pin fin heat sink
}

\author{
Venkatesh Saravanan ${ }^{1 *}$, Chitradurga K. Umesh ${ }^{2}$, Doddamani Hithaish ${ }^{2}$, Kanakanahalli Seetharamu $^{3}$ \\ ${ }^{1}$ Department of Mechanical Engineering, BNMIT, Bangalore (560070), India \\ ${ }^{2}$ Department of Mechanical Engineering, UVCE, Bangalore (560001), India \\ ${ }^{3}$ Department of Mechanical Engineering, PESU, Bangalore (560085), India
}

Corresponding Author Email: saravanan.venkatesh@gmail.com

https://doi.org/10.18280/ijht.360136

Received: 30 August 2017

Accepted: 2 Feburary 2018

\section{Keywords:}

micro channel, micro pin fin, heat sink, square pin fin, circular pin fin, fined micro channel

\begin{abstract}
Cooling of miniature size electronic components has become challenging for designer in the development of integrated circuits. Micro pin fin heat sink and Micro channel pin fin heat sink is one of the thermal management technique for effective cooling. The paper presents comparison of fluid flow and heat transfer characteristics for micro pin fin heat sink and micro channel pin fin heat sink with UN finned micro channel heat sink. A Three Dimensional heat sink with water as coolant subjected to constant heat flux $10 \mathrm{~W} / \mathrm{cm}^{2}$, for Reynolds number ranging between100-900 is considered for study. Extended surfaces of different shapes namely square and circular with staggered arrangement is considered for both micro pin fin heat sink and micro channel pin fin heat sink. Two non-dimensional parameter namely nusselt number and thermal performance index is employed to access the performance of heat sink. Results indicate Micro channel pin fin heat sink has highest nusselt number and friction factor over the whole Reynolds number range. Results also revealed that formation of secondary vortices enhances heat transfer in micro channel heat sink with square pin fin compared to micro channel heat sink with circular pin fin. However pin fin heat sink has better thermal performance index compared to Micro channel pin fin heat sink and is more preferable when heat dissipation is compared with pressure drop penalty. The Governing equations for fluid and solid domain are solved using FLUENT 6.2 to study flow and heat transfer characteristics.
\end{abstract}

\section{INTRODUCTION}

With rapid development in power electronics. Thermal management of small sized electronic components has become highly challenging for designer. The components are highly delicate and the critical factor which determines the life span is operating temperature. Care has to be taken to maintain the maximum surface temperature beyond safe limit, failing would hinder long term operation of electronic devices. Presently the researcher has proposed a solution to dissipate larger heat flux by employing micro pin fin heat sink and micro channel heat sink for efficient cooling. These heat sink are fabricated using micro machining techniques and are advantageous where parameters like thermal resistance and heat transfer coefficient are concerned. They have a low thermal resistance, high heat transfer coefficient, greater heat transfer surface area and require minimum inventory which are favorable for heat dissipation. Moreover, these heat sinks are slightly modified by having either staggered or inline pin fin arrangements which prove to be more effective. It has the potential to dissipate larger magnitude of heat through smaller areas with an increase in the pressure drop.

The concept of micro channel was first proposed by Tuckerman and Pease [1], Shafeie et al. [2] numerically studied performance of heat sink with staggered and oblique arrangement and observed Oblique pin fin performs better compared to staggered for a given pumping power.
Hydrodynamic and Heat transfer characteristics have been explored numerically for heat sink with pin fin structures by TurkerIzci et al. [3], Hasan et.al [4] numerically compared hydrodynamic and heat transfer characteristics of micro pin fin heat sink of different shapes using water and Nano fluids. Sohail et al. [5] proposed pin fin array of various shapes to reduce maximum surface temperature. Later Abdoli et al. [6] numerically investigated the influence of different pin fin shapes for cooling of electronic chips and reported pin fin with convex and hydrofoil shape perform better compared to circular cross section. Carlos et al. [7] proposed variable fin density heat sink of different shapes namely circle, square, elliptical and flat plate to maintain uniform temperature of integrated chips. Flat shaped pin fins were observed to be superior compared to other shapes. Liu et al. [8] experimentally proved pin fin shape has significant effect on heat transfer at larger Reynolds number. Yavo poles et al. [9] experimentally proved thermal resistance can be greatly reduced by employing pin fin heat sink. Zhao et al. [10] experimentally showed elliptical pin fin has better stream line with low thermal resistance and triangular pin fin has larger flow resistance compared to other shapes. John et al. [11] proposed a non-dimensional zed parameter to access the performance of pin fin heat sink and proved circular fins are effective for Reynolds number smaller than 300 and square fins are better for Reynolds number greater than 300. Kosar and Peles et al. [12] compared the performances of micro pin 
fin heat sink of different shapes namely circular, rectangular, hydrofoil, and cone-shaped. They concluded at high Reynolds number pin fin with denser configuration has better performance, whereas sparsely configuration is better at low Reynolds number. BayramSahin et al. [13] experimentally proved heat sink with square pin fin results in heat transfer enhancement and developed correlation for enhancement efficiency.

Judy et al. [14] investigated pressure drop through micro channels with different cross sections. Lee et al. [15] experimentally investigated heat transfer in rectangular micro channels, effect of surface roughness on micro channel heat sink was studied by Giulio et al. [16]. Welin Qu et al. [17, 18] conducted experiments through micro channel heat sink and compared the experimental results using three dimensional conjugate model numerically, later viscosity model and roughness viscosity model were proposed to interpret experimental data. Dorinlelea et al. [19] experimentally studied performance of micro tubes using distilled water. Reiyucheien et al. [20] numerically investigated micro channel heat sink with different inlet and outlet arrangements and concluded heat sink performs better when coolant is collected vertical. Harms et al. [21] reported micro channel heat sink with smaller width and larger depth performs better. Marino et al. [22] reported experimental results for heat transfer in micro channel heat sink. Peng et al. [23] experimentally studied influence of geometry on the performance of micro channel and concluded heat transfer under laminar regime is highly dependent on aspect ratio. Wu et al. [24] experimentally predicted transition zone for flow inside microchannel and showed hydrodynamic and heat transfer characteristics increases with surface roughness. Zhang [26] proposed parallel and counter flow micro channel heat sink with bifurcations to minimize micro channel heat sink temperature. Results reveal that counter flow heat sink performs better than parallel flow and by employing bifurcation the thermal performance can be greatly enhanced. Yadav et al. [28] studied the performance of micro channel with extended surface at different position. Pankaj et al. [30] numerically studied the effect of ribs and cavities on fluid flow and heat transfer in convergent divergent micro channel, result show that use of ribs and cavities reduces the overall thermal resistance and maintains uniform temperature. Abdullaha et al. [31] numerically investigated heat transfer, flow and entropy in a three dimensional cavity via heat sink subjected to natural convection.

As discussed above, studies available in open literature are mostly focussed on heat sink with different pin fin shapes and rectangular micro channel heat sink. None of the studies reports the combined effect of pin fin heat sink and micro channel heat sink. The prime focus of present investigation is to study the combined effect of pin fin heat sink and micro channel heat sink.

\section{DESCRIPTION OF PHYSICAL MODEL}

\subsection{Un finned micro channel heat sink}

The overall dimensions of Un finned micro channel heat sink is shown in figure 1a. An aluminum substrate of size $11.5 \mathrm{~mm}$ X $6 \mathrm{~mm}$ with a total of 5 channels are considered for present work. The geometrical parameters of rectangular micro channel heat sink are channel width $0.75 \mathrm{~mm}\left(\mathrm{~W}_{\mathrm{ch}}\right)$,
Channel Height $1 \mathrm{~mm}\left(\mathrm{H}_{\mathrm{ch}}\right)$, heat sink width $1.125 \mathrm{~mm}\left(\mathrm{~W}_{\mathrm{s}}\right)$, Wall Thickness $0.375 \mathrm{~mm}(\mathrm{Wt})$, substrate thickness $0.375 \mathrm{~mm}$ (ts). Owing to symmetric condition and to reduce the computational time, single element of micro channel heat sink is considered for computational model as shown in figure $1 \mathrm{~b}$. Unfinned micro channel heat sink is considered to be the base line heat sink to compare the performance of pin fin heat sink and micro channel pin fin heat sink. This is taken as case a.

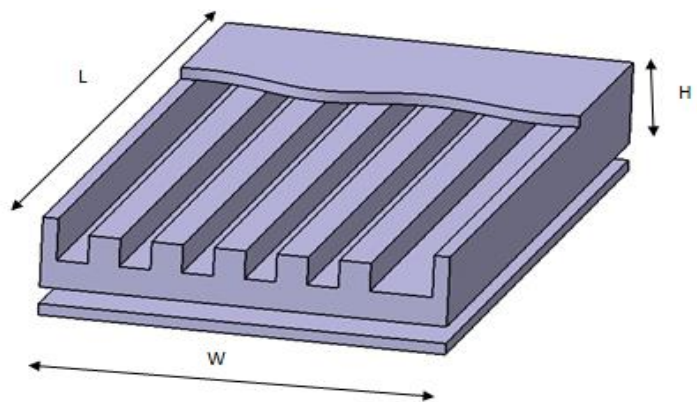

Figure 1a. Three dimensional arrangement of un finned micro channel heat sink (Case a)

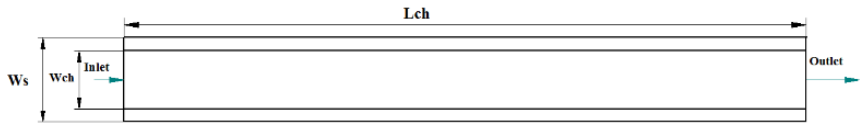

Figure 1b. Top view of single element micro channel heat sink

\subsection{Pin fin heat sink}
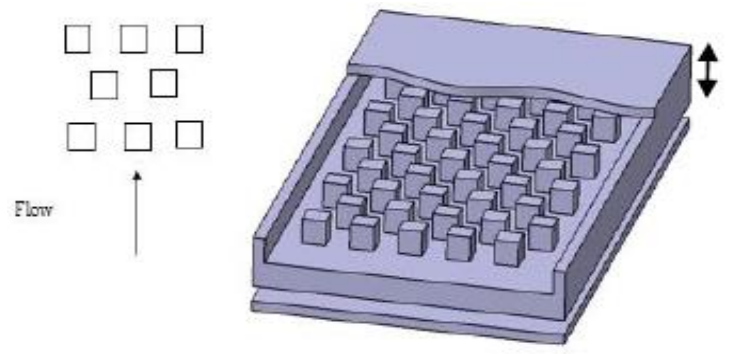

Hch

Figure 2a. Three dimensional arrangement of staggered heat sink with square pin fin (Case b)

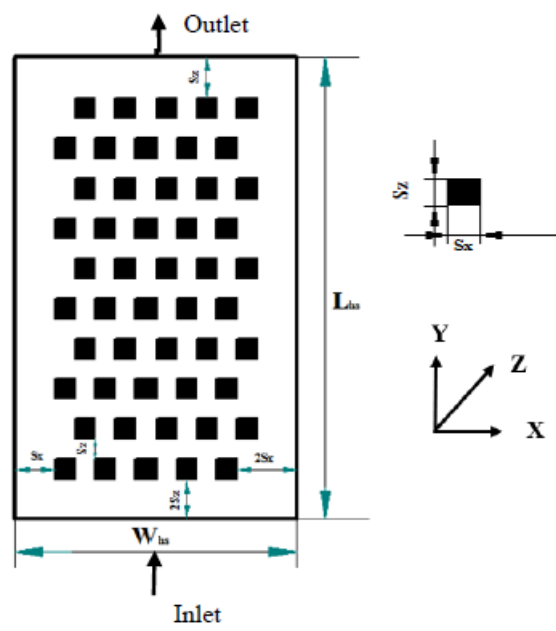

Figure 2b. Top view of staggered arrangement of heat sink with square pin fin 


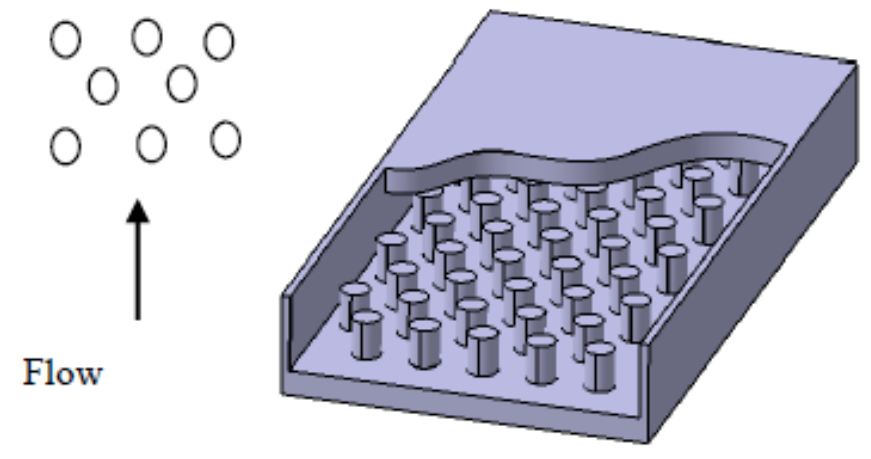

Figure 2c. Three-dimensional arrangement of staggered heat sink with circular pin fin (Case c)

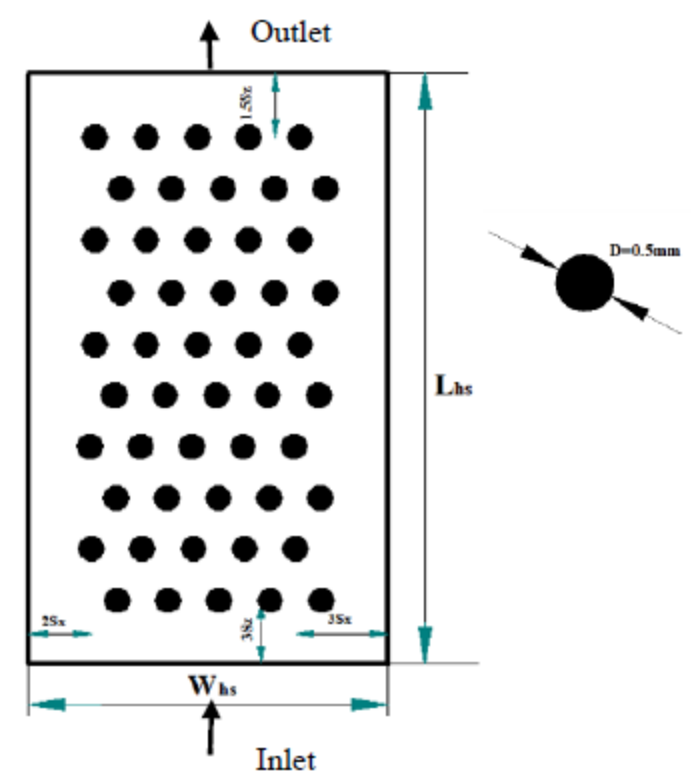

Figure 2d. Top view of staggered arrangement of heat sink with circular pin fin

A Three Dimensional heat sink of dimensions $11.5 \mathrm{~mm} \mathrm{X}$ $6 \mathrm{~mm} \mathrm{X} \mathrm{1mm,} \mathrm{[4]} \mathrm{with} 50$ square pin fins of size $0.5 \mathrm{~mm} * 0.5 \mathrm{~mm}$, height $0.5 \mathrm{~mm}$ is considered for square pin fin heat sink [case b] and 50 circular pin fins of diameter $0.5 \mathrm{~mm}$, height $0.5 \mathrm{~mm}$, is considered for circular pin fin heat sink [case c] as shown in Figure 2a,2b,2c and $2 d$ respectively . Further, staggered arrangement of fins spaced with distance of $0.5 \mathrm{~mm}$ is considered. Ten pin fins are considered in longitudinal direction and five in traverse direction. Longitudinal and transverse distance between pin fin are $\mathrm{S}_{\mathrm{x}}=\mathrm{S}_{\mathrm{z}}=0.5 \mathrm{~mm}$.

\subsection{Micro channel pin fin heat sink}

A micro channel heat sink of same dimensions discussed in section 2.1 with staggered arrangement of square and circular pin fin are considered and represented by case $d$ and case $e$ respectively. Ten pin fins are considered in the longitudinal direction as shown in Figure $3 \mathrm{a}$ and $3 \mathrm{~b}$ respectively. The dimensions of square pin fin are $0.5 \mathrm{~mm} X 0.5 \mathrm{~mm}$ and diameter of circular pin fin is $0.5 \mathrm{~mm}$. The spacing fin distance are $\mathrm{Sx}=0.5 \mathrm{~mm}$ and $\mathrm{Sz}=0.5 \mathrm{~mm}$ respectively. To investigate flow and heat transfer characteristics of heat sink, water was used as working fluid and aluminum heat sink with constant properties [4] as shown in table 1 .

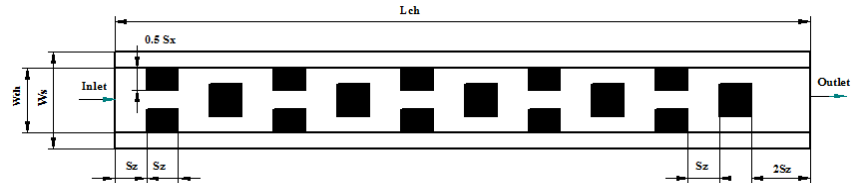

Figure 3a. Top view of single element micro channel heat sink with square pin fin (case d)

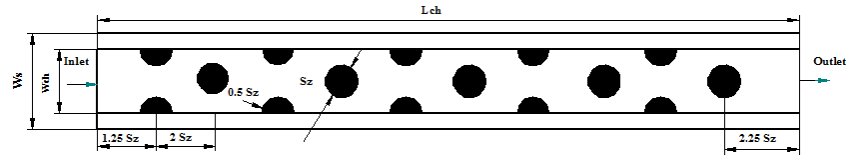

Figure 3b. Top view of single element micro channel heat sink with circular pin fin (case e)

Table 1. Properties of coolant and heat sink

\begin{tabular}{|c|r|r|r|r|}
\hline & $\begin{array}{c}\rho \\
\left(\mathrm{kg} / \mathrm{m}^{3}\right)\end{array}$ & $\begin{array}{c}\mathrm{c}_{\mathrm{p}} \\
(\mathrm{J} / \mathrm{kg}-\mathrm{K})\end{array}$ & $\begin{array}{c}\mathrm{K} \\
(\mathrm{W} / \mathrm{m}-\mathrm{k})\end{array}$ & $\mu(\mathrm{kg} / \mathrm{m}-\mathrm{s})$ \\
\hline Fluid (water) & 981.3 & 4189 & 0.643 & 0.000598 \\
\hline Heat Sink & 2719 & 871 & 273 & ------- \\
\hline
\end{tabular}

\subsection{Assumptions}

The following assumptions were made to simplify the problem
i.) Flow is steady and laminar
ii.) Fluid is Newtonian and incompressible.
iii.) No slip condition at walls.
iv.) There is no viscous dissipation
v.) Body forces are neglected.

\subsection{Governing Equation and parameter definition}

Based on the above assumption, the following equation is solved to compute velocity and temperature distribution [4]

Continuity equation:

$$
\nabla \cdot(\rho . \mathrm{V})=0
$$

Momentum equation:

$(u . \nabla) \rho V=-\nabla P+\mu \nabla^{2} V$

Energy equation:

$\mathrm{V} . \nabla T=\frac{K}{\rho C_{p}} \nabla^{2} T$

Governing equation for heat sink is given by

$\nabla^{2} T=0$

Reynolds number at inlet is defined as:

$\operatorname{Re}=\frac{\rho u d_{h}}{\mu}$ 
where $\rho$ is the fluid density, $u$ is the inlet velocity, $d_{h}$ is the hydraulic diameter and $\mu$ is the fluid dynamic viscosity.

$d_{h}=\frac{4 A}{\operatorname{Pr}}$

$\mathrm{A}=\mathrm{W}_{\mathrm{s}} \mathrm{X} \mathrm{L}_{\mathrm{s}}$ for pin fin heat sink and $\mathrm{A}=\mathrm{W}_{\mathrm{s}} \mathrm{X} \mathrm{L}_{\mathrm{ch}}$ for micro channel pin fin heat sink, $\mathrm{Pr}$ is the perimeter.

The maximum thermal resistance is evaluated using the relation:

$R_{\max }=\frac{T_{\text {max }}-\mathrm{T}_{\text {in }}}{q}$

$\mathrm{T}_{\max }$ is the maximum temperature of the bottom substrate and $\mathrm{q}$ is the heat flux dissipated by the bottom substrate.

The average nusselt number is computed using the relation:

$N u=\frac{\mathrm{h}_{\mathrm{m}} \mathrm{d}_{\mathrm{h}}}{K}$

$h_{m}=\frac{Q}{n A\left(T_{\text {avg }}-T_{\text {in }}\right)}$

The required friction factor is calculated using the relation:

$f=\frac{2 . \Delta P}{\rho \cdot \mathrm{u}^{2}{ }_{\text {max }}}$

\subsection{Boundary condition}

The fluid velocity was computed based on flow Reynolds number $\operatorname{Re}=\frac{\rho u d_{h}}{\mu}$ and imposed at inlet where $d_{h}$ is the hydraulic diameter. The inlet fluid temperature at the entry was set to be Tin $=293 \mathrm{~K} . \mathrm{u}=\mathrm{v}=0, \mathrm{w}=\mathrm{w}_{\text {in }}$ and $\mathrm{T}=\mathrm{T}_{\text {in }}$.

The flow is assumed to be fully developed at the outlet of the channel and zero velocity is defined at the solid boundaries. Uniform heat flux is imposed upon the bottom surface of the solid substrate, adiabatic condition was assumed for side walls in case of pin fin heat sink and symmetry condition for micro channel heat sink with pin fin, the upper wall was considered to be adiabatic.

\subsection{Solution methodology}

The governing conservative continuity, momentum and energy equations was solved using the Finite Volume Method. Convective terms were discretized using second order upwind scheme and a simple algorithm was adopted for pressure-velocity coupling to obtain the pressure field. Segregated solver was used to solve the conservation scheme. For convergence residual criteria $10^{-6}$ was used for continuity equation and velocity in all direction, whereas $10^{-7}$. for energy equation. The convergence criteria for conservative equations was set to $10^{-6}$. The entire work was carried out using FLUENT software.

The grid independency was studied for heat sink with square pin fin with bottom wall temperature maintained at $373 \mathrm{~K}$ for Reynolds number 100 with pure water as coolant. To ensure grid independency of the results, three different grid sizes were studied: 2, 21,661 (coarse), 8, 21,778 (intermediate) and 14, 26,121(finer). The difference between obtained outlet temperature and pressure drop for different grid size is less than $1 \%$ as shown in table 2, thus a computational grid with 2,21,661 elements was sufficient for study, which gives same result with minimum computational time. Table 2 summarizes the outlet temperature and pressure drop for three different gird size.

Table 2. Mesh independent study

\begin{tabular}{|c|c|c|}
\hline $\begin{array}{c}\text { Number of } \\
\text { elements }\end{array}$ & $\begin{array}{c}\text { Outlet temperature } \\
(\mathrm{K})\end{array}$ & $\begin{array}{c}\text { Pressure drop } \\
(\mathrm{pa})\end{array}$ \\
\hline $2,21,661$ & 324.83 & 13.98 \\
\hline $8,21,778$ & 325.12 & 14.09 \\
\hline $14,26,121$ & 325.31 & 14.21 \\
\hline
\end{tabular}

\section{RESULTS AND DISCUSSION}

\subsection{Validation}

The Fluent code was validated with the experimental results from literature [18]. in which, the model presented consists of rectangular Micro Channel of dimensions $231 \mu \mathrm{m}$ X $731 \mu \mathrm{m}$ (Case a). Deionized water was employed as coolant and test was conducted for $100 \mathrm{~W} / \mathrm{cm}^{2}$ for Reynolds number ranging between 200 to1600.The difference between present simulation and analytical solution was very negligible. The results are validated for pressure drop and temperature drop. Figure. 4 shows comparison of computed pressure drop with experimental values for increasing Reynolds number. Since pressure drop is directly proportional to square of velocity, pressure drop increases with Reynolds number. Computed pressure drop from the present work slightly under predicts experimental values. The deviation may be due to losses with sudden expansion and contraction at entry and exit of micro channel. Which is not considered while carrying out computational work. Figure. 5 shows comparison of temperature drop with experimental values for different Reynolds number. The temperature drop decreases with Reynolds number and are in good agreement with experimental results.

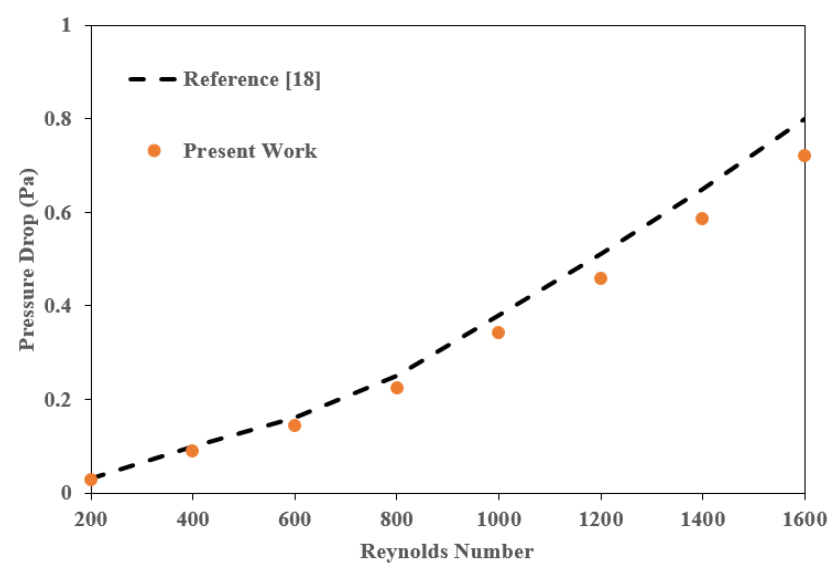

Figure 4. Comparison of pressure drop computed from present work with experimental results [18] 


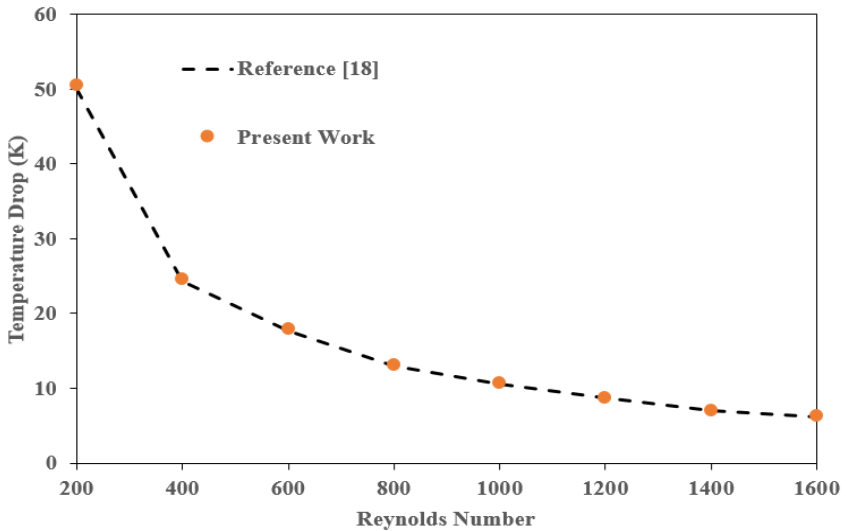

Figure 5. Comparison of Temperature drop (Tout-Tin) computed from present work with experimental results [18]

\subsection{Pressure drop}

Figure. 6 illustrates variation of pressure drop (difference between upstream and downstream pressure) with Reynolds number for different cases discussed above. As expected pressure drop in micro channel pin fin heat sink is high compared to pin fin heat sink and un finned micro channel heat sink. In case of un finned Micro channel heat sink, when working fluid flows inside confined channel, the viscous shear effect produced due to side walls is highly dominant and contributes to total pressure drop. It can be observed Case $\mathrm{d}$ has largest pressure drop compared to other cases. Both form drag and friction drag contribute to total pressure drop. When fluid passes around sharp corners, as in case of Case $b$ and case $d$, the flow around pin fin leads to form drag, the combined effect of viscous shear and separation around sharp corner contribute to increase in total pressure drop. Whereas due to stream line separation in Case c and Case e, pressure drop is slightly less than square pin fin. For all the cases pressure drop is minimum for lower flow velocity and increases with flow velocity. At low velocity, fluid viscosity and pin fin surface are responsible for boundary layer formation around pin fin. Wall effects are highly significant and high wall shear stress is responsible for pressure drop [12].

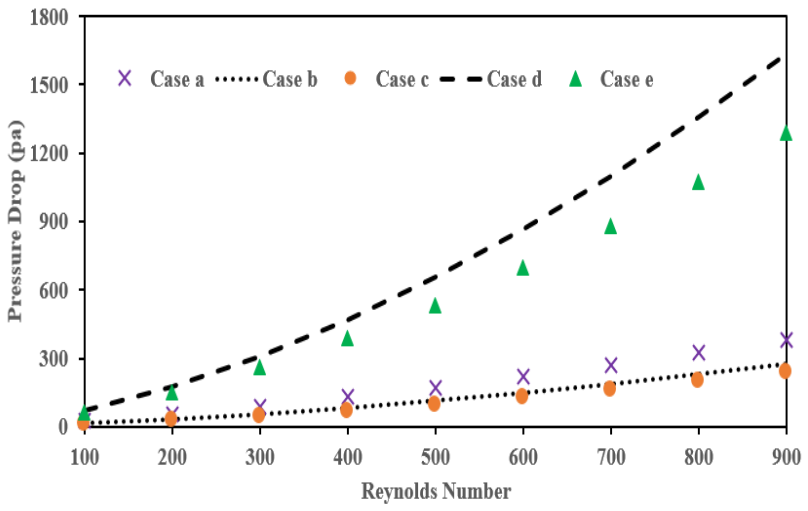

Figure 6. Variation of Pressure drop with Reynolds number for different cases of heat sink

On the other hand, the wall effects become weaker and insignificant with increases in flow velocity, the force exerted by fluid due to pin fin surface increases, leading to boundary layer separation from pin fin surface and vortex formed are shed into wake resulting in very rapid rise in pressure drop. Pressure drop for case e increases by $63 \%$ in comparison with Case $\mathrm{c}$ and for Case $\mathrm{d}$ it increases by $58 \%$ in comparison with Case $b$ respectively. Hence pressure drop increases with Reynolds number for all cases.

\subsection{Friction factor}

Friction Factor decreases with Reynolds number, however at certain Reynolds number it reaches a constant value and remain constant thereafter. This trend is observed for all cases and are slightly inconsistent which is mainly due to the influence of different forces. The total forces exerted by fluid around solid surface is sum of forces exerted due to shear stress along flow direction namely frictional resistance and swirl resistance generated due to asymmetrical pressure distribution. At low flow velocity, frictional resistance is more compared to swirl resistance, due to the absence of vortex shedding the resistance offered is mainly due to friction. Due to inverse pressure gradient and end wall effect separation occurs at high Reynolds number leading to vortex generation which is carried away from wake zone. The effect of swirl resistance increases with Reynolds number and becomes more dominant compared to frictional resistance. Hence frictional factor decreases with Reynolds number and remain constant due to inertia. Circular pin fin is more stream line leading to delay in boundary layer separation and smaller wake zone compared to square pin fin as shown in Figureure. 7. The effect of larger surface area can be the reason behind the larger pressure drop due to the friction drag [27].

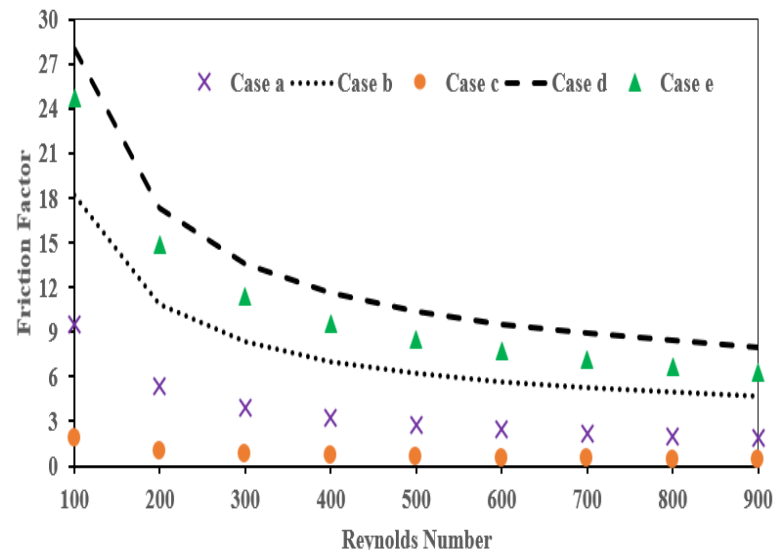

Figure 7. Variation of friction factor with Reynolds number for micro pin fin and micro channel heat sink

\subsection{Temperature drop}

Figure. 8 shows the temperature drop with Reynolds number for different cases discussed above. At low flow velocity fluid travels at slower rate absorbing maximum heat from heat sink resulting in rise in outlet temperature. Whereas at high flow velocity fluid travels at faster rate absorbing minimum heat leading to minimum rise in bulk temperature. At low Reynolds number heat transfer due to diffusion plays a key role for rise in outlet temperature and forced convection heat transfer plays a key role for drop in outlet temperature at high Reynolds number [29]. Flow around case c and case e is more stream line resulting in intense mixing of fluid leading to increase in bulk temperature at outlet. Whereas in case of square pin fin, fluid flow is accelerated due to separation at 
sharp corners leading to drop in outlet temperature as seen in case $b$ and case $d$. Hence Temperature drop for circular pin fin is slightly on the higher side compared to square pin fin for both pin fin heat sink and micro channel pin fin heat sink.

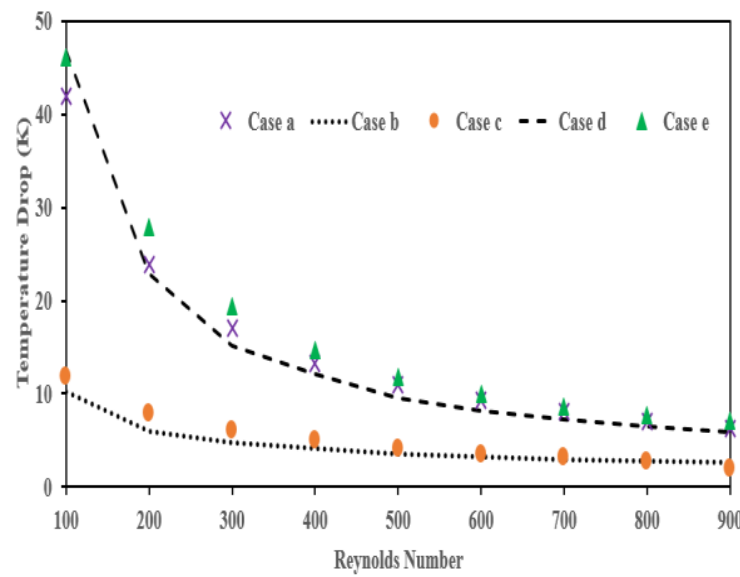

Figure 8. Variation of Temperature drop with Reynolds number for micro pin fin and micro channel heat sink

\subsection{Maximum thermal resistance}

Figure. 9 shows variation of Maximum thermal resistance with Reynolds number for different cases of heat sink. For all cases of heat sink, thermal boundary layer thickness decreases with Reynolds number resulting in maximum heat transfer thereby decrease in thermal resistance. For flow around case $\mathrm{b}$ and case $\mathrm{d}$, fluid separates around sharp corners triggering flow separation and promoting fluid mixing [12]. The wakes formed around square pin fin are large compared to circular pin fin leading to decrease in thermal resistance as shown in Figure 11 and 12.

Maximum thermal resistance for case $d$ and case e are low compared to case $b$ and case $c$. The main reason is that, in case of micro channel heat sink with pin fin the combined effect of axial conduction phenomenon along flow direction and forced convection leads to decrease in thermal resistance; whereas the axial conduction effect is highly negligible for pin fin heat sink leading to increase in thermal resistance. This shows that axial conduction plays a key role in enhancing heat transfer for micro scale [8]. Thermal resistance for case d decreases by $42 \%$ in comparison with case $b$ whereas for case e decreases by $57 \%$ compared to case c respectively.

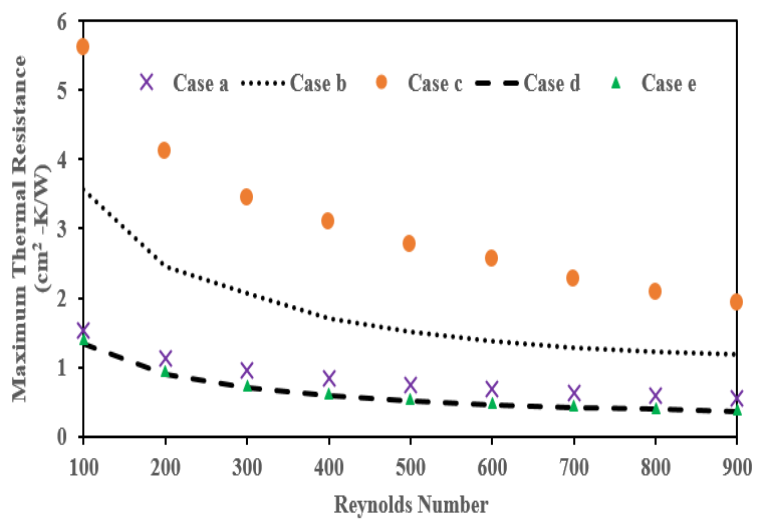

Figure 9. Variation of thermal resistance with Reynolds number

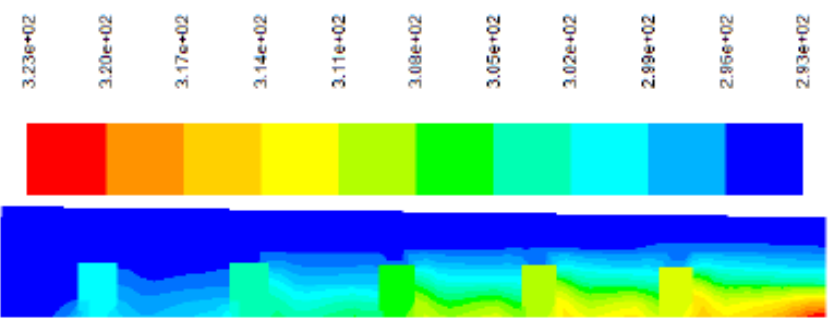

(i) Case a

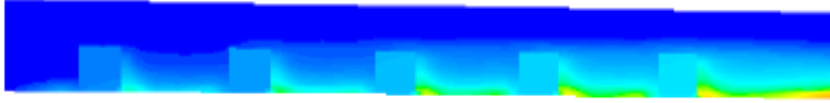

(ii) Case b

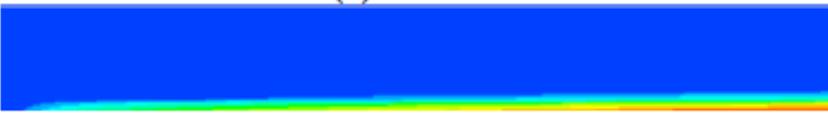

(iii) Case c

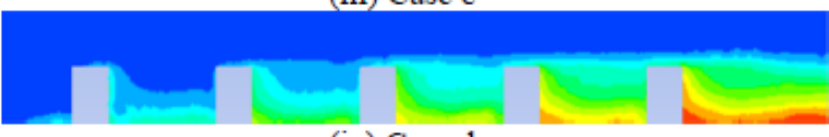

(iv) Case d

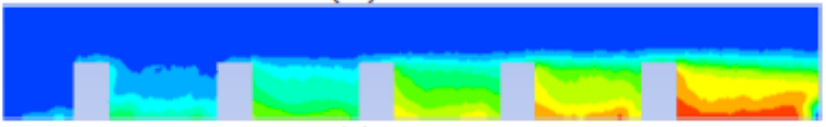

(v) Case e

Figure 10. Temperature $(\mathrm{K})$ contour along the symmetric plane passing through central vertical line for different cases of heat sink

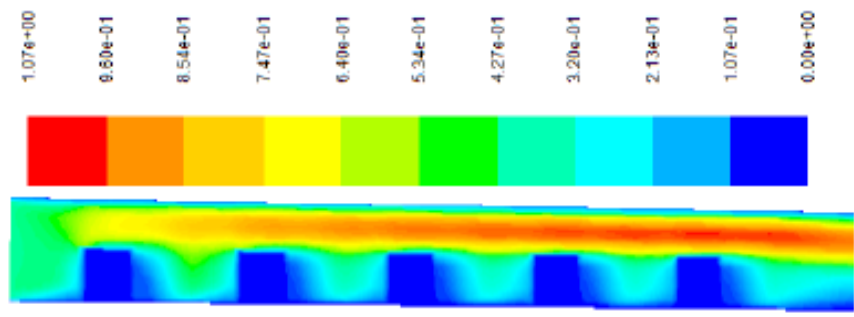

(i) Case a

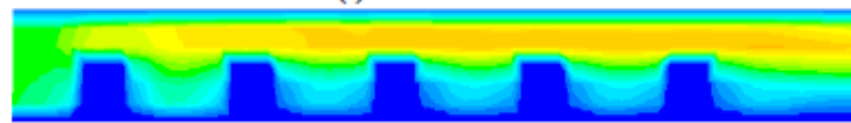

(ii) Case b

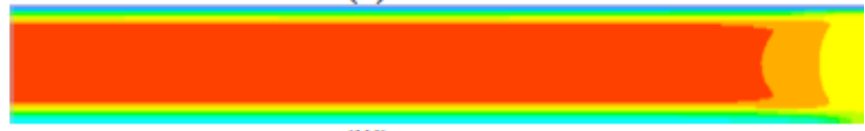

(iii) Case c

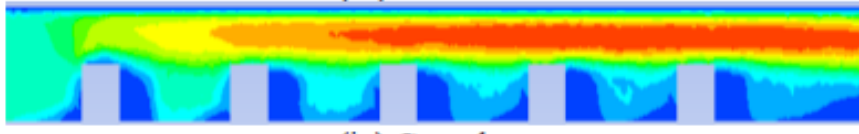

(iv) Case d

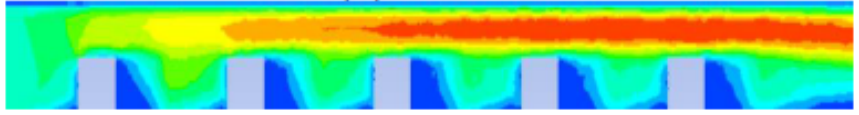

(v) Case e

Figure 11. Velocity $(\mathrm{m} / \mathrm{s})$ contour along the symmetric plane passing through central vertical line for different cases of heat sink

\subsection{Flow pattern}

Figure. 10 and Figure. 11 illustrates temperature distribution and velocity distribution slice taken from the centre line along the symmetry plane for different cases. The temperature at the entry is $293 \mathrm{~K}$ everywhere. The 
temperature rise starts at the upstream point of the flow domain, and the heated fluid layer becomes thicker as it gets closer to the outlet as shown in Figure. 10. While the temperature for different cases would certainly change along the longitudinal direction. For all cases, temperature distribution is maximum at the corner of heat sink since there is negligible amount of heat dissipation due to convection. The minimum temperature occurs at the entry of heat sink which is mainly due to higher heat transfer coefficient at the entry. The presence of pin fin interrupts the temperature profile and does not allow the boundary layer to grow to fully developed state as shown in Figure. 10. Due to flow interruption there is a redevelopment in thermal boundary layer resulting in better fluid mixing thereby increasing heat transfer. Along with this heat transfer is further enhanced due to the presence of pin fins. Figure. 11 indicates the average flow velocity is high for case $d$ and case e compared to case $b$ and case c. higher flow velocity brings about more heat transfer from hot surface to coolant thereby contributing to enhancement in heat transfer which in turn reduces the surface temperature of heat sink. The stream line across Case $\mathrm{d}$ and Case e for different Reynolds number is shown in Figure. 12 and Figure. 13. When the flow velocity increases, the force exerted by fluid from pin fin surface increases leading to flow separation around pin fin and wake formation. Increase in flow velocity promotes flow separation leading to increase in larger wake zone [3]. From the stream line contour, it is very clear that secondary vortices are formed for both Case $\mathrm{d}$ and Case e, this may be due to influence of turbulence promoting flow separation at low Reynolds number. Formation of secondary vortices is delayed for Case e compared to case $d$ due to stream line separation. When Reynolds number increases from 100 to 900, length of recirculation zone increases from $0.38^{*} 10^{-3} \mathrm{~m}$ to $0.49 * 10^{-3} \mathrm{~m}$ for Case $\mathrm{d}$ and $0.3 \times 10^{-3} \mathrm{~m}$ to $0.42 \times 10^{-3} \mathrm{~m}$ for Case e. Recirculation zone is broader for pin fin with sharp corners compared to stream line separation showing pronounced flow separation leading to intense mixing of fluid resulting in heat transfer enhancement.

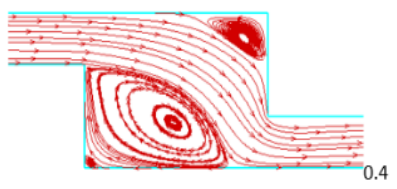

a) $\operatorname{Re}=100$

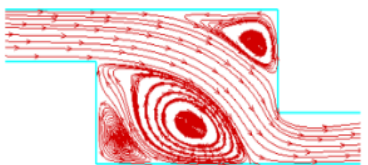

c) $\mathrm{Re}=500$

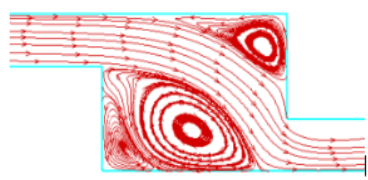

e) $\operatorname{Re}=900$ b) $\operatorname{Re}=300$

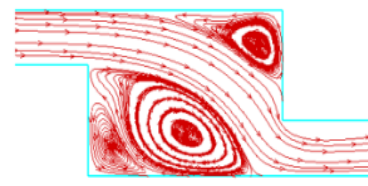

d) $\operatorname{Re}=700$

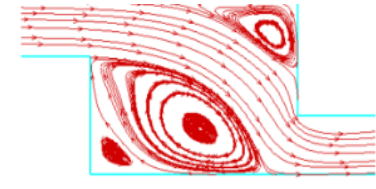

Figure 12. Stream line contour with Reynolds number for case $\mathrm{d}$

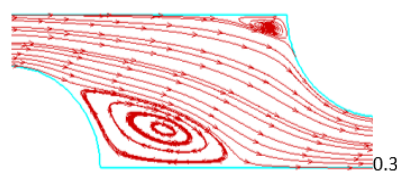

a) $\operatorname{Re}=100$

c) $\operatorname{Re}=500$

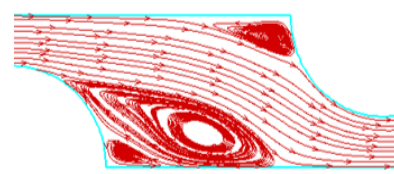

e) $\operatorname{Re}=900$

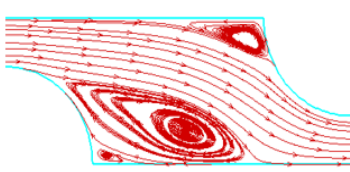

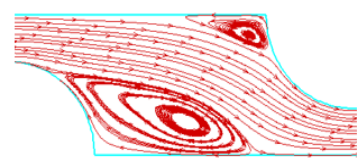

b) $\operatorname{Re}=300$

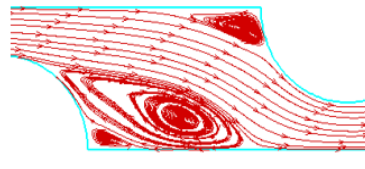

d) $\operatorname{Re}=700$
Figure 13. Stream line contour with Reynolds number for case e

\subsection{Nusselt number}

Figure 14 demonstrates nusselt number as a function of Reynolds number for different cases. As expected nusselt number increases with Reynolds number for all the cases. Nusselt number for micro channel pin fin heat sink (Case $\mathrm{d}$ and Case e) and pin fin heat sink (Case b and Case c) are high compared to un finned micro channel heat sink (Case a), which is mainly due to the presence of extended surfaces. The temperature profile for case $b$, case c, case $d$ and case e is highly disrupted due to the presence of pin fins as shown in Figure 10 and Figure 11, thereby not allowing the Thermal boundary layer to reach the fully developed state. This disruption is due to the presence of pin fins leads to redevelopment of thermal boundary layer [28], also the presence of pin fin intensifies flow separation absorbing maximum heat from solid pin fins and increasing heat transfer. The collective effect of redevelopment of boundary layer and better fluid mixing is responsible for increase in nusselt number for heat sink with pins. The Nusselt number trend for pin fin heat sink is similar to result obtained in numerical study by [3].

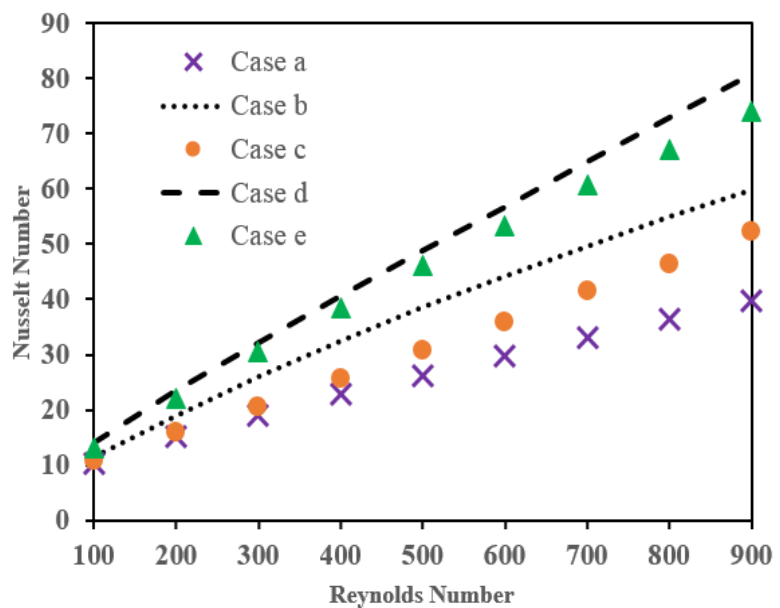

Figure 14. Variation of nusselt number with Reynolds number for different cases of heat sink 
The performance of heat sink based on nusselt number form higher to lower value are in the order case d, case e, case $b$, case $c$ and case a. Pin fins with sharp corners triggers flow separation and has larger surface area compared to circular pin fin, hence heat sink with square pin fin performance better compared to circular pin fin. The main objective of the study was to decrease the maximum surface temperature and enhance high heat transfer rate. By employing micro channel with pin fin the conduction heat transfer can be highly enhanced compared to pin fin heat sink resulting in higher heat transfer rate thereby reducing surface temperature.

\subsection{Thermal performance index}

The presence of extended surface in pin fin heat sink and micro channel pin fin heat sink has better heat transfer performance compared to un finned micro channel with rise in pressure drop. Hence a non-dimensional parameter namely thermal performance index (TPI) is defined to study the overall performance of pin fin heat sink and micro channel heat sink by comparing with un finned micro channel. Thermal performance index is defined as $\eta=\frac{N u / N u_{O}}{\left(\Delta P / \Delta P_{o}\right)^{1 / 3}}$ [3]. Figure. 15 shows the variation of thermal performance index with Reynolds number subjected to $10 \mathrm{~W} / \mathrm{cm}^{2}$. This clearly shows the overriding rise in overall pressure drop compared to increase in heat transfer. For fluid flow in case $d$ and case e the intensity of velocity fluctuation is more rapid compared to case $\mathrm{b}$ and case c. Micro channel pin fin heat sink (case d and case e) are highly sensitive to end wall effect the same penetrates to main flow more rapidly compared to pin fin heat sink (case b and case c) leading to increase in pressure drop. Hence in terms of TPI, pin fin heat sink is considered to be superior compared to micro channel pin fin heat sink.

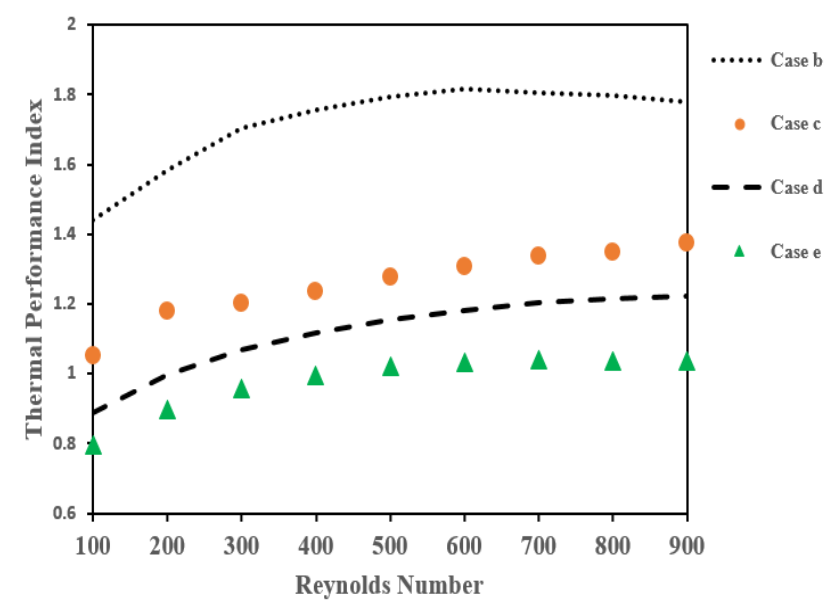

Figure 15. Thermal performance index with Reynolds number for different cases of heat sink

\section{CONCLUSION}

In the present work, experimentally tested system was numerically modelled at Reynolds number between 200 to 1600. The numerical results were compared with experimental data to show the credibility of numerical method. Later thermal hydraulic performance of pin fin heat sink and micro channel pin fin heat sink was compared with un finned micro channel heat sink based on pressure drop, friction factor, nusselt number, performance index and stream contours. Based on the present work the following conclusions were drawn.

[1] Due to the combined effect of axial conduction phenomenon and convective heat transfer in micro channel pin fin heat sink, case $d$ and case e are observed to be far superior compared to pin fin heat sink (case b and case c) in terms of heat transfer enhancement, indicating Micro channel pin fin heat sink can be significantly better alternative for pin fin heat sink.

[2] Highest heat transfer enhancement is observed in case d compared to other cases. This is mainly due to larger surface area as in case of square fin promoting flow separation at corners compared to stream line separation resulting in enhanced heat transfer. The results agree with [12].

[3] Thermal performance index based on un finned micro channel heat sink increases with Reynolds number and case $b$ has highest performance index compared to other cases, which shows case b would be better alternative when combined effect of heat transfer and pressure drop is considered.

[4] The formation of secondary vortices for case $d$ has strong influence on enhancement of heat transfer compared to case e.

[5] The pressure drop increases with flow velocity and is sufficiently large for fluid flow with sharp separation compared to stream line separation for both micro channel pin fin heat sink and pin fin heat sink. Pressure drop for case e increases by $63 \%$ compared to case c whereas for case $\mathrm{d}$ it increases by $58 \%$ compared to case b respectively.

\section{REFERENCES}

[1] Tuckerman DB, Pease RFW. (1981). High-performance heat sinking for VLSI, IEEE Electronic Devices Letters 2: $\quad$ pp. 126-129. https://doi.org/ 10.1109/EDL.1981.25367

[2] Shafeie H, Abouali O, Jafarpur K, Ahmadi G. (2013). Numerical study of heat transfer performance of singlephase heat sinks with micro pin-fin structures, Applied Thermal Engineering 58: 68-76. https://doi.org/ 10.1016/j.applthermaleng.2013.04.008

[3] Izcia T, Koza M, Koşara A. (2015). The effect of micro pin-fin shape on thermal and hydraulic performance of micro pin-fin heat sinks, Heat Transfer Engineering 36(17): 1447-1457. https://doi.org/ $10.1080 / 01457632.2015 .1010921$

[4] Hasan MI. (2014). Investigation of flow and heat transfer characteristics in micro pin-fin heat sink with nanofluid, Applied Thermal Engineering 63: 598-607. https://doi.org/ 10.1016/j.applthermaleng.2013.11.059

[5] Sohail RR, Abas A, Dulikravich GS, Pacheco CC, Genesis V, Rajesh J, Marcelo JC, Helcio RBO. (2015). Multi-Objective Optimization Of Micro Pin-Fin Arrays For Cooling Of High Heat Flux Electronics With a Hot Spot Proceedings of the ASME 2015 International Technical Conference and Exhibition on Packaging and Integration of Electronic and Photonic Microsystems and ASME. https://doi.org/ 10.1115/IPACK2015-48242 
[6] Abdoli A, Jimenez G, Dulikravich GS. (2015). Thermofluid analysis of micro pin-fin array cooling configurations for high heat fluxes with a hot spot, International Journal of Thermal Sciences 90: 290-297. https://doi.org/ 10.1016/j.ijthermalsci.2014.12.021

[7] Rubio-Jimenez CA, Kandlikar SG, Hernandez-Guerrero A. (2012). Numerical analysis of novel micro pin fin heat sink with variable fin density IEEE transactions on components. Packaging And Manufacturing technology 2(5): 825-833. https://doi.org/ 10.1109/TCPMT.2012.2189925

[8] Liu ZG, Guan N, Zhang CW, Jiang GL. (2015). The flow resistance and heat transfer characteristics of micro pin-fins with different cross-sectional shapes. Nanoscale and Microscale Thermo Physical Engineering 19: 221243. https://doi.org/ 0.1080/15567265.2015.1073820

[9] Peles Y, Kosar A, Mishra C, Kuo CJ, Schneider B. (2005). Forced convective heat transfer across a pin-fin micro heat sink. International Journal of Heat and Mass Transfer 48: 3615-3620. https://doi.org/ 10.1016/j.ijheatmasstransfer.2005.03.017

[10] Zhao HX, Liu ZG, Zhang CW, Guan N, Zhao HH. (2016). Pressure drop and friction factor of a rectangular channel with staggered mini pin fins of different shapes. Experimental Thermal and Fluid Science 71: 57-69. https://doi.org/ 10.1016/j.expthermflusci.2015.10.010

[11] John TJ, Mathew B, Hegab H. (2010). Parametric study on the combined thermal and hydraulic performance of single phase micro pin-fin heat sinks part I: Square and circle geometries. International Journal of Thermal Science 49: 2177-2190. https://doi.org/ 10.1016/j.ijthermalsci.2010.06.011

[12] Kosar A, Peles Y. (2006). Thermal-hydraulic performance of MEMS-based pin fin heat sink. ASME Journal of Heat Transfer 128: 121-131. https://doi.org/ $10.1115 / 1.2137760$

[13] Sahin B, Demir A. (2008). Performance analysis of a heat exchanger having perforated square fins. Applied Thermal Engineering 28: 621-632. https://doi.org/ /10.1016/j.applthermaleng.2007.04.003

[14] Judy J, Maynes D, Webb BW. (2002). Characterization of frictional pressure drop for liquid flows through micro channels. International Journal of Heat and Mass Transfer 45: 3477-3489. https://doi.org/ 10.1016/S0017-9310(02)00076-5

[15] Lee PS, Garimella SV, Liu D. (2005). Investigation of heat transfer in rectangular microchannels. International Journal of Heat and Mass Transfer 48: 1688-1704. https://doi.org/ 10.1016/j.ijheatmasstransfer.2004.11.019

[16] Croce G, D'agaro P, Nonino C. (2007). Threedimensional roughness effect on microchannel heat transfer and pressure drop. International Journal of Heat and Mass Transfer 50: 5249-5259. https://doi.org/ 10.1016/j.ijheatmasstransfer.2007.06.021

[17] Qu WL, Mohiuddin Mala Gh, Li DQ. (2000). Heat transfer for water flow in trapezoidal silicon micro channels. International Journal of Heat and Mass Transfer 43: 3925-3936. https://doi.org/ 10.1016/S00179310(00)00045-4

[18] Qu WL, Mudawar I. (2002). Experimental and numerical study of pressure drop and heat transfer in a single-phase micro-channel heat sink international.
Journal of Heat and Mass Transfer 45: 2549-2565. https://doi.org/ 10.1016/S0017-9310(01)00337-4

[19] Lelea D, Nishio S, Takano K. (2004). The experimental research on micro tube heat transfer and fluid flow of distilled water. International Journal of Heat and Mass Transfer 47: 2817-2830. https://doi.org/ 10.1016/j.ijheatmasstransfer.2003.11.034

[20] Chein RY, Chen JH. (2009). Numerical study of the inlet/outlet arrangement effect on microchannel heat sink performance. International Journal of Thermal Sciences 48: 1627-1638. https://doi.org/ /10.1016/j.ijthermalsci.2008.12.019

[21] Harms TM, Kazmierczak MJ, Gerner FM. (1999). Developing convective heat transfer in deep rectangular microchannels. International Journal of Heat and Fluid Flow 20: 149-157. https://doi.org/ 10.1016/S0142727X(98)10055-3

[22] Morini GL. (2004). Single-phase convective heat transfer in microchannels a review of experimental results. International Journal of Thermal Sciences 43: 631-651 10.1016/j.ijthermalsci.2004.01.003

https://doi.org/

[23] Peng XF, Peterson GP, Wang BX. (1994). Frictional flow characteristics of water flowing through rectangular microchannels. Experimental Heat Transfer 7: 249-264. https://doi.org/ $10.1080 / 08916159408946484$

[24] Wu HY, Cheng P. (2003). An experimental study of convective heat transfer in silicon micro channels with different surface conditions. International Journal of Heat and Mass Transfer 46: 2547-2556. https://doi.org/ 10.1016/S0017-9310(03)00035-8

[25] Shah RK, London AL. (1978). Laminar flow forced convection in ducts. A Source Book for Compact Heat Exchanger Analytical Data, Suppl. 1, Academic press, New York.

[26] Zhang FL, Sunden B, Zhang WH, Xie GN. (2015). Constructal parallel-flow and counterflow microchannel heat sinks with bifurcations, Numerical Heat Transfer, Part A 68: 1087-1105. https://doi.org/ 10.1080/10407782.2015.1023148

[27] Munson BR, Young DF, Okiishi TH. (1998) Fundamental of Fluid Mechanics, 3rd.Wiley, New York, 591-610.

[28] Yadav V, Baghel K, Kumar R, Kadam ST. (2016). Numerical investigation of heat transfer in extended surface. Microchannels International Journal of Heat and Mass Transfer 93: 612-622. https://doi.org/ 10.1016/j.ijheatmasstransfer.2015.10.023

[29] Seyf HR, Feizbakhshi M. (2012). Computational analysis of nanofluid effects on convective heat transfer enhancement of micro-pin-fin heat sink. International Journal of Thermal Sciences 58: 168-179. https://doi.org//10.1016/j.ijthermalsci.2012.02.02

[30] Srivastava P, Dewan A, Bajpai JK. (2017). Flow and heat transfer characteristics in convergent-divergent shaped microchannel with ribs and cavities. International Journal of Heat and Technology 35(4): 863-873. https://doi.org/ 10.18280/ijht.350423

[31] Al-Rashed AAAA, Kolsi L, Oztop HF, Abu-Hamdeh N, Borjini MN. (2017). Natural convection and entropy production in a cubic cavity heated via pin-fins heat sinks, International journal of heat and Technology 35(1): 109-115. https://doi.org/ 10.18280/ijht.350115 


\section{NOMENCLATURE}

A

C

d

$\mathrm{H}$

$\mathrm{h}$

K

$\mathrm{L}$

$\mathrm{Nu}$

$\mathrm{n}$

$\mathrm{p}$

$\operatorname{Pr}$

Q

q

$\mathrm{R}$

Re

$\mathrm{S}$

$\mathrm{T}$

TPI

$\mathrm{u}, \mathrm{v} \mathrm{w}$

$\mathrm{V}$
Cross sectional area $\left(\mathrm{m}^{2}\right)$

Specific heat $(\mathrm{J} / \mathrm{Kg} \mathrm{K})$

Diameter (m)

Height

Heat Transfer co efficient $\left(\mathrm{W} / \mathrm{m}^{2} \mathrm{~K}\right)$

Thermal conductivity (W/m K)

Length ( $m$ )

Nusselt Number

Number of fins

Pressure

Perimeter

Heat dissipated (W)

Heat flux $\left(\mathrm{w} / \mathrm{m}^{2}\right)$

Thermal Resistance $\left(\mathrm{cm}^{2}-\mathrm{K} / \mathrm{W}\right)$

Reynolds Number

spacing distance (m)

Temperature

Thermal performance index

Velocity in $\mathrm{x}, \mathrm{y}$ and $\mathrm{z}$

Velocity component $(\mathrm{m} / \mathrm{s})$
W

width

$\mathrm{x}, \mathrm{y}, \mathrm{z}$

Coordinates

\section{Greek symbols}

$\begin{array}{ll}\rho & \text { Density }\left(\mathrm{Kg} / \mathrm{m}^{3}\right) \\ \Delta & \text { Delta } \\ \mu & \text { Dynamic Viscosity }(\mathrm{Kg} / \mathrm{m} \mathrm{s})\end{array}$

\section{Subscripts}

avg

Average

ch

channel

fluid

Hydraulic

Inlet

un finned micro channel

Outlet

sink

Surface

thickness 